\title{
The idea of beauty in the piano cycle "Childhood Birds" by Konstantin Iliev
}

\author{
Krasimira Georgieva Fileva-Ruseva \\ Faculty of Music Pedagogy, Academy of Music, Dance and Fine Arts - Plovdiv, Bulgaria, Europe \\ Email address: \\ krassyfilleva@abv.bg
}

To cite this article:

Krasimira Georgieva Fileva-Ruseva. The Idea of Beauty in the Piano Cycle "Childhood Birds" by Konstantin Iliev. International Journal of Literature and Arts. Special Issue: Musical Theory, Psychology and Pedagogy. Vol. 2, No. 5-1, 2014, pp. 1-7.

doi: $10.11648 /$ j.ijla.s.2014020501.11

\begin{abstract}
There is beauty everywhere in nature. Sometimes even creatures, that we are used to consider unsightly, burst with it. Looking more closely, ignoring the traditional view, we find colour combinations, proportions, movements that get surprisingly beautiful as soon as we realize it. In art the depiction of beauty could take different forms as well as it could take most unexpected characters for its prototypes. Such kind of beauty reveals to us the small gallery of characters - the piano cycle "Childhood Birds" by the Bulgarian composer Konstantin Iliev. It is comprised of six plays. In this piano cycle I analyze the beauty of the characters - for example the little sweet-voiced nightingale, where the beauty lies in its skilful singing, i.e. in what it can do; unlike the rose, on which the bird is perched, where the beauty lies in its symmetry, proportionality and grace - in being what it is. The swallows are beautiful with the audacity to struggle with the fierce mighty wind. An example of the beauty of the construction is the classical regularity of the built-up musical forms; the slight diversions from which are prompted by the specific representational tasks in each play. The beauty of depiction lies in the outspoken and compelling description of all the images by means of ingeniously found and utmost concise means. The cycle as a whole is an example of yet another type of beauty - the beauty of invention, of creativeness, of discovering a wonderful in its clarity and brevity way of recreating a character so that it can be perfectly recognized, to breath life into it, to give it emotions and meaning, the beauty of an artist to "dare" to materialize through sound the elusive immateriality of a dream, the beauty to challenge the imagination of the performer and make the listener soar, the beauty of the mind.
\end{abstract}

Keywords: Music, Piano Work, Beauty, Musical Analysis, Konstantin Iliev

\section{Introduction}

There is beauty everywhere in nature. Sometimes even creatures, that we are used to consider unsightly, burst with it. Looking more closely, ignoring the traditional view, we find colour combinations, proportions, movements that get surprisingly beautiful as soon as we realize it. In art the depiction of beauty could take different forms as well as it could take most unexpected characters for its prototypes. Such kind of beauty reveals to us the small gallery of characters - the piano cycle "Childhood Birds" by the Bulgarian composer Konstantin Iliev. It is comprised of six plays.

\section{Objects, Aim, Subject and Tasks of the Study}

The objects of this study are the six pieces of the piano cycle "Childhood Birds" by Konstantin Iliev.

The aim is to reveal the different types of beauty, permeating the little collection of musical characters.

The subjects of the study are the ways and means by which the composer achieves the exquisiteness of the miniatures and "teach" the pianists, studying the little works, beauty.

The tasks, deriving from thus stated objective, are:

- Discovering the beauty of the characters, portrayed with musical means of expression;

- Highlighting the beauty of the musical structure;

- Clarifying the beauty of expression. 


\section{The Beauty of the Characters}

Beauty could be tender, fragile, touching, heroic, brilliant...

"The Little Nightingale on the Rose Bush" is a real triumph of beauty. Because the very title and the specificity of the musical exposé presuppose the existence of two characters which do not contrast each other, nor are they in conflict with each other, i. e. there are no reasons to look out for the contradiction of a positive and a negative character, of beautiful and not beautiful, and the two images "co-exist" successfully and rather complement one another, we could assume the presentation and the interaction of two types of beauty. The ethereal trills and tremolos in the high register represent the carefreeness of the bird song. The great dynamic amplitudes - a crescendo from pianissimo to forte and then damping from poco forte to pianissimo, carried out during a short period of time, the fine variations in the "deepness" of the sound as for instance amplification from pianissimo to piano, as well as the abrupt dynamic contrasts, like crescendo from mezzo forte, followed by pianissimo, create the idea of a singer who has got a superb control over his voice. The short arpeggio-like movements evoking the view of "fluttering" around the rose, after which the song starts over again without any discernible effort, as well as the repeated "initiations" every time from one and the same harmonic interval strengthen the impression that the little sweet-voiced creature sings as easily and naturally as it breathes. The rose is depicted in a different way - through repeated ascending arpeggio movement in the lower voice, starting from bar 2. The four identical arpeggios, which are not affected by the melodic motion in the upper voice, i.e. it could be said that they are a texture element, independent of the melody - a separate image, leave the impression of harmony and undisturbed tranquillity. The arpeggio itself possesses an internally symmetric structure - major third small third - major second - small third - major third.

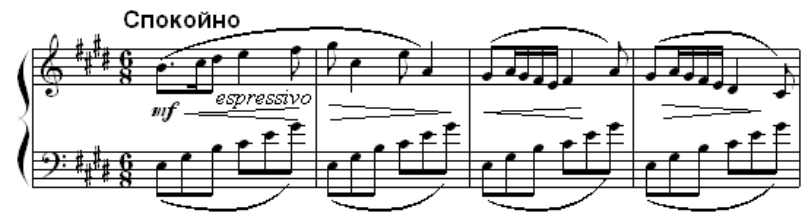

Figure 1. "The Little Nightingale on the Rose Bush", b. 2 - 5

The fact that symmetry in art is regarded as a manifestation of staticity supports the assumption that this melodic structure (it is not an accompaniment as it does not show functional dependence on the melodic movement in the upper voice) depicts the static, motionless personage the rose bush. The strict symmetry is also a token of classic beauty and harmony. The even, uninterrupted quaver rhythm in its turn suggests calm, fluent rhythmicity, and the metric pulsation - a six-beat meter - further creates the feeling of ethereal grace. Whereas at the beginning the arpeggio-like movement is found in the middle register, from the sixth bar it transits to a higher register; and its structure is slightly modified: three literal repetitions of an upward movement, followed by a symmetrical reversal of each of the two triads, composing the arpeggio. This resembles the desire of the sculptor to add a tiny imperfection to his creation so that to achieve the sense of realism. This construction - three similar elements and the fourth one different is repeated in bars $12-13,14-15$ and $18-19$; but this time the elements are twice as short. In bars $16-17$ the first type repetitiveness is restored - the four elements being the same. In bars $12-15$ "the stillness" is marked through the pedal point on $\mathrm{h}$ (the texture plan now is of two lines; the melodically active voice in quaver pulsation is the higher one; in the lower voice the $\mathrm{h}$ tones have a duration of dotted halves); in bars $16-17$, the feeling of stillness is invoked by the repeated $\mathrm{g}^{1}$ tones. In all the structures in the higher voice of the two-voiced texture plan, the even quaver pulsation is constantly preserved. It helps to discern the component of the musical texture in which the image of the rose bush is "encoded", no matter in which voice the repeated elements are conducted.

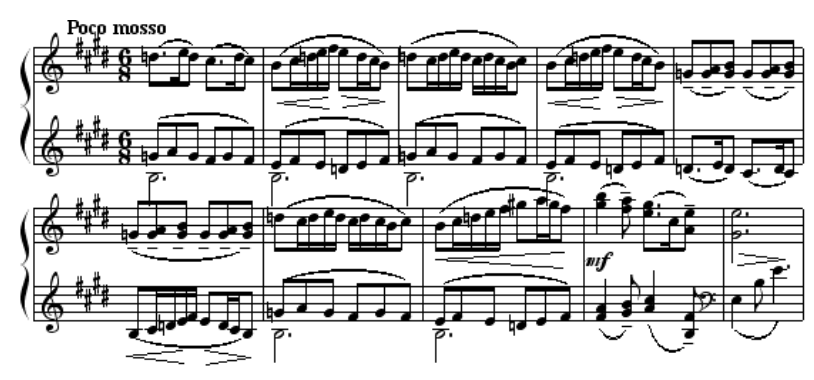

Figure 2. "The Little Nightingale on the Rose Bush", b. 12 - 21

A shortened repetition follows - the appearance of only the first two bars of each of the two four-bar sequences of the beginning of the mensural part of the piece - bars $2-3$ are repeated in bars $22-23$, and bars 6-7-in bars $24-25$. This perfect proportionality completes the idea of the classical elegance of the rose bush. Whereas in the partition of bars $12-27$, the little nightingale carelessly "calls out" from various tone pitches; sometimes it has to take great "leaps" so that its melody could be heard now in the high, now in the lowest voice as if the singer peeps out from different branches of the bush, in all the moments in which the texture plan, depicting the rose, changes its location compared to "the melody of the bird", an even transition is procured which also contributes to the impression of the depiction of the bush's branches. This rule is neglected only in the cadences. While in the onomatopoeic introduction and conclusion there is no meter and the song flows freely and unrestrictedly, in the mensural partition the melody changes substantially (the type of change is discussed later on in this exposition). As if the natural elegance and symmetry of the rose bush "provokes" the sensitive artist to respond to its proportionality. It means that the admirable co-existence of a nightingale and a rose in this play is also a symbol of something much deeper - of the meeting of Nature - natural beauty - and Art - the skills of the little singer who is able to improvise carelessly, unhindered by any rules or 
requirements, as well as to skilfully imitate natural beauty.

In "The Dream of the Little White Dove" is represented the beauty of tranquillity. The broad, even, melodic lines with continuous motions in one direction and comparatively great diapason are calm, free and undisturbed just like a flight, like soaring up in the sky. The texture is also extremely transparent and "airy" - throughout the whole piece the exposition is two-voiced, usually one of the voices repeating one and the same motif. The eighths on the first beat of each bar, provided by the voice with the repeated motif, being the shortest notes in this motif, overcome the weight of the strong metric moment (breaking it up) and in addition to this they lend easiness and freedom of the musical texture.

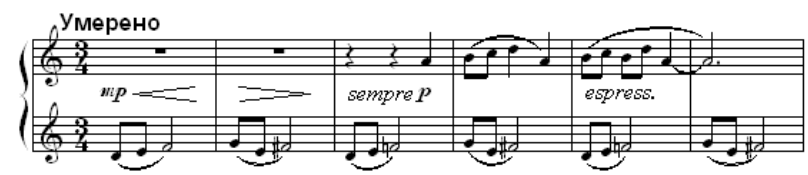

Figure 3. "The Dream of the Little White Dove", b. 1 - 6

The idea of tranquillity and calmness is alluded to in the title itself. The white dove is a universal symbol of peace. The clear specification from the title itself - the little white dove, gives a hint to both the performer and the listener about the conception of the composer - the sleepy calmness of the little bird and the diminutive name which leads the associations to something small and tender as well as the fine nuances with which this is reproduced in the musical exposition - the delicacy of the variable third degree in the repeated motif express the tender, touching beauty of its calmness.

In "The Northern Wind Chasing the Swallows", are recreated the beauty of braveness of the fighting spirit. The ascending and descending gamma-like successions in all registers, with quick and large dynamic amplitudes (from piano up to forte in bars $1-3$, from piano up to fortissimo in bars 30 - 32) more likely characterize the wind. The northern wind is usually violent and cold; and the sound in the low register is generally associated with darkness and burden. The reasons for this are:

- The tones of the low register i. e. the ones with a greater wavelength, compared to the higher tones, are projected over a bigger surface of the brain structures responsible for processing the sound information [2]. In the same way, a greater part of the brain cells, assimilating motor impulses, is charged when processing the information of a heavy object rather than of a light one. The similarity between the pairs of senses (low - high sound and heavy - light) is the reason why the low tones are assimilated also as heavy and the higher ones - as lightweight.

- Light is an absolutely necessary condition for the functioning of the visual analyser. Lighting enables the change of light-colour stimuli which causes an excitatory effect on the brain - thus providing the activity of the brain cells in charge of the processing of information. The high sound frequencies possess a greater number of vibrations, compared to the lower ones, which leads to a more frequent change of the processes of activity and passivity of the perceiver. This means that "the cells responding to the higher sounds more often systematically relax which secures their greater activity in the process of perception" (,клетки, реагирующие на высокие звуки чаще имеют систематический отдых, что обеспечавает их большей активностью при восприниманием”) [2, p. 60]. The similarity in the function of the visual and the acoustic analyser determines the analogy high sound - light, low sound - darkness. In the cold seasons, autumn and winter, when the northern wind blows more often, the greater part of the twenty-four hour period is dark. We also associate darkness with "the dark forces". All that leads us to regard the wind as the negative character and the big dynamic amplitudes, the abrupt turns in the direction of the gamma-like movement, used to describe it - as fierce, wrathful and mighty. The other basic types of movement - short arpeggios mostly in the high register - depict the swallows. The range of the arpeggio - a diminished octave (only in one of the cases - enharmonic major seventh) - provokes the feeling of anxiety, as well as of great effort connected with the difficult attempts with which the little birds try to stick around the vicinity they love and how hard they try not to leave their places. The rather dense dynamics - forte, mezzo forte, fortissimo - additionally suggest tension and effort. The fact that every other structure in which the arpeggio motion emerges, begins from a higher tone (the high register of the piano resounds sharp when it is played loudly) even more distinctly illustrates the strenuous, hard struggle of the swallows against the raving gusts of the wind. Although in the end of the play the swallows are chased away and the evil force triumphs, it is beautiful when you are so tiny to dare to fight against the fierce might of the storm.

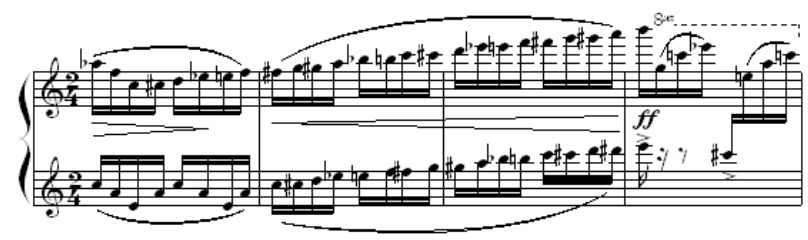

Figure 4. "The Northern Wind Chasing the Swallows", b. 20-23

The composer has paid special attention to the play "The Little Hen Laid an Egg" - in it is depicted the successful character of the cycle; its image being situated in a prominent position - in the middle of the matched miniatures. In "The Little Hen Laid an Egg”, the author very often instructed changes in the dynamics - crescendo and diminuendo. In musical works in slow tempo, the melodic line usually is saturated with many dynamic changes which vividly underline its punctuation. And vice versa, in quick 
tempo is usual the more general thinking. When the melodic line is detailed with so frequent variations in the dynamics in a work in fast tempo, as it is in the discussed piece, it is hard for the listener to follow them; for that reason the frequent dynamic changes are regarded as a sign of flamboyance or in the case of "The Little Hen Laid an Egg" - of hastiness.

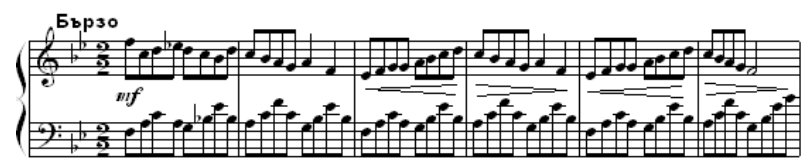

Figure 5. "The Little Hen Laid an Egg”, b. 7-12

The short turning motions in the melody, similar to a tongue-twister, and the quick ascending gamma-like successions with "incomplete" reversed movements highlight this characteristic. The build-up to the culmination is bright, attractive and memorable.
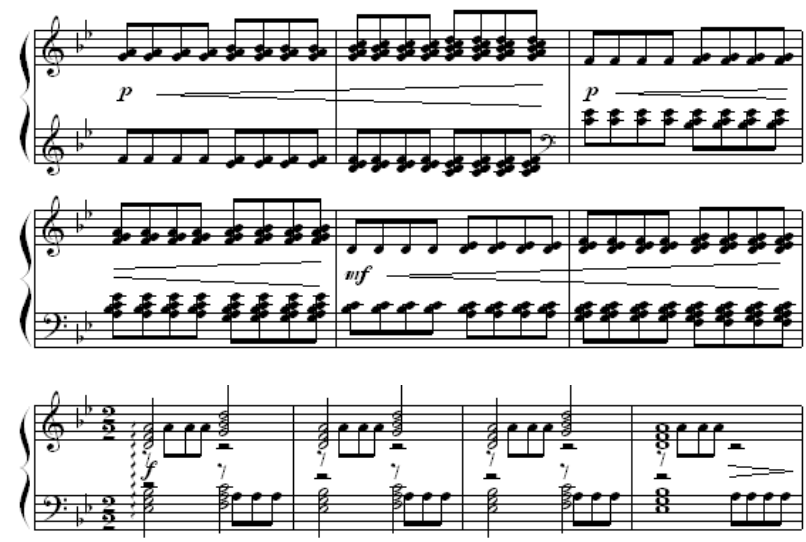

Figure 6. "The Little Hen Laid an Egg”, b. 13-22

As if in a celebration of success - the little hen is the only positive character in this cycle that has led its act to a successful end - the spectacular culmination is onomatopoeic (imitating its "voice"). The onomatopoeic culmination does not appear in any other piece of this cycle. In the short reprise, the small hen, having announced its accomplishment in the culmination, modestly, with its initial hastiness, goes back to its habitual busy life.

\section{The Beauty of the Construction}

The structure of the musical image could also be beautiful.

Apart from the second miniature - "The Dream of the Little White Dove" and the last one - "The Northern Wind Chasing The Swallows", the rest of the plays follow the same "scheme" - introduction and conclusion formed by an onomatopoeic element, and in the middle there is a "song", lending additional clarity in the character's characteristic.

The first play - "The Sparrow at the Window" - is built up by 5-bar introduction and conclusion, in both of these sections the third bar is a pause; and a period with a repeated structure, consisting of two four-bar half-sentences, the first one made up of two identical phrases; the second phrase of the second half-sentence begins like the first one but the end is different to ensure the conclusion. The brilliant simplicity and proportionality have not prevented Mr. Iliev from expressing the insistent questioning of the little sparrow, left out in the cold without anybody to take care of it and with its quiet despair and exhaustion.

The different audible representation tasks in "The Dream of the Little White Dove" have influenced the structure of the piece as well. The two-bar introduction is followed by three four-bar phrases, and in the last two phrases the melody stretches into six bars, i.e. it gradually extends. In the first half-sentence the repeated motif is carried out by the lower voice and has four appearances, in the next half-sentence the characteristic melodic structure is repeated in the high voice and has three literal repetitions; in the last half-sentence the motif resounds once again in the low voice but the literal repetitions are only two (after them it appears changed), as if the repeated, the familiar one, quietly and gradually fades away. Since the familiar motif (after a great number of repetitions) is perceived as an anchor, its gradual surmount till the end of the piece ( $4-3-2$ literal repetitions) with the fluent extension of the duration of the phrases in the melody (4-4-4-6-6 bars) and their range (perfect forth, minor seventh, perfect fifth, perfect eleventh, octave), with almost mathematical precision recreate the tranquil dissolving and falling into the non-material flight of the dream.

The construction of the "The Little Hen Laid an Egg" is very orderly - the half-sentences follow one almost "rhythmical" continuation - a four-bar onomatopoeic introduction, two four-bar half-sentences of the first period, a six-bar build-up to the culmination, a four-bar onomatopoeic culmination, an "impatiently" shortened up to a common duration of six bars reprise, four-bar onomatopoeic conclusion ( $4-4-4-6-4-6-4$ bars). The culmination is prepared with a very strict and linear downward sequence which adds new features to the portrait of the successful character. The culmination coinciding (bars 19 - 22) with the point of the Golden Ratio (which in this piece is calculated in bar 20) additionally provides for the classical properties of the play.

The structure of the fourth piece - "The Little Cuckoo in the Forest" - reflects certain stagnation. The eight-bar onomatopoeic introduction is followed by a period of three eight-bar half-sentences, the last of them fusing with the five-bar onomatopoeic conclusion. There is no bright culmination. The highest tone in the piece is $a^{2}$ (bar 18), which is expected to bring the highest point of tension, is reached while in the accompanying texture plan a continuous gradual descending movement of parallel fifths is maintained; this doesn't allow for the higher melodic tone to sound as a vivid emotional peak. The second high point (the $\mathrm{f}^{2}$ from bar 22 ) is less clearly expressed in the melody (it has already been reached once), but, unlike the first one, it appears during the only change in the lower texture plan to an ascending line of shorter tone durations from the moment in which this texture 
plan receives the accompanying role (i.e. from bar 9). This adds a certain amount of tension to the $f^{2}$ in bar 22 .

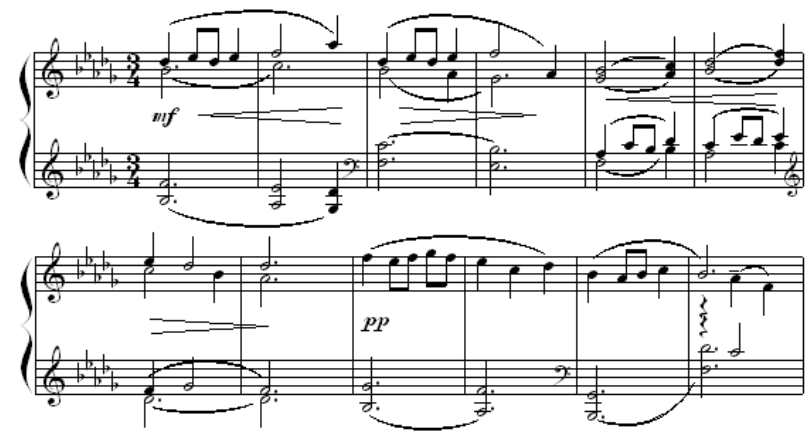

Figure 7. "The Little Cuckoo in the Forest", b. 17-28.

Both peaks however are located in a weak metrical moment (the third beat), which also prevents them from truly becoming a clear culmination and adds to the feeling of gloominess, of dispersal of the peak moments. In the introduction another similar "voice" answers to the call of the cuckoo, while in the melodically formed period and in the onomatopoeic conclusion in the second voice, in which a sound-imitating descending minor third is heard, it is not present - there is no answer to the insistently repeated call. This particularity of the onomatopoeia, the half-hearted culminations, the elegiac melody and the "empty", bar-long parallel sixths and fifths in the accompanying texture plan (in no other piece in the cycle is the accompaniment so stagnant) portray in an unambiguous and powerful way the loneliness of the bird.

In "The Little Nightingale on the Rose Bush" not only the texture plan, representing the rose, is classically structured. The melody, regardless if it is in the soprano or in the lower voice, is also influenced by this evenness, but in a different way. The section of bars $2-5$ consists of two phrases. The one in bars $2-3$ is made of three elements with the same range: $h^{1}-$ fis $^{2}, \operatorname{cis}^{2}-$ gis $^{2}, a^{2}-e^{1}$. The next phrase shows a little variation. It consists of two motifs with a range of $\mathrm{e}^{1}-$ $\mathrm{a}^{1}$ and cis $^{1}-\mathrm{a}^{1}$ respectively. When it appears anew in bars 6 -9 the first phrase is a repetition of the one from bars $2-3$, and the motifs of the second have a tone range $\mathrm{e}-\mathrm{a}$ and cis1 $-\mathrm{g}^{1}$. The phrases in bars $12-13$ and $16-17$, similarly to the phrase in bars $2-3$, both consist of three elements (the phrase in bars $16-17$ is a repetition of the one in bars $12-13$, but an octave lower, exactly as the phrase in bars $6-7$ repeats the one from bars $2-3$ in an octave lower), while in the $14^{\text {th }}$ bar and its repetition in the $18^{\text {th }}$ bar, the first two sub-motifs are combined in one common figure, i.e. the phrases in bars $14-15$ and $18-19$ each consists of two motifs. This again is similar to the structure of the phrases of bars $4-5$ and $8-9$ (consisting of two motifs) in relation to those in bars $2-3$ and $6-7$ (consisting of three elements). This analysis shows the repetitiveness and the co-relation, achieved through exact rules and in the framing of the melody; it reveals certain symmetry, as if the classical elegant proportionality and beauty of logic have spread their well proportioned influence even over the free-willed, but sensitive and receptive forest singer. Additionally, a feeling of classical elegance of the measured partition is created by the cadence, the same in all of its three appearances (bars 10 - 11, $20-21$ and $26-27$ ), glamorizing each of the more complete musical phrases, similar to the lines of a choir in an Ancient Greek Theatre.

In the "Northern Wind Chases the Swallows" the forces seeming equal until a certain moment (the birds manage to hold their positions against the attacks of the wind for a certain time), is reflected in the structure of the piece through the equal duration of the sections, in which the characters are depicted - after the two-bar initial air-blast, the gamma-like builds alternate every four bars with ones of arpeggio movements, and the fact that the culmination is preluded in only one of these four-bar sections i.e. there is no continuous build-up, shows once again, that the "victory" of the force of nature has been achieved after a battle with inconstant success. The triumph of the wind is revealed in a way, that once again illustrates the struggle of achieving superiority - through two abrupt, separated by pauses two-bar builds, and the last (the third) stretched to four bars with a fading from fortissimo to piano, which reflects the wind quieting down.

\section{The Beauty in the Expression}

When the means of expression are mastered to a degree of virtuosity, even the smallest character can be described beautifully and impressively.

In "The Sparrow at the Window" the lack of a prominent dominant in the harmony creates certain coldness, further underlined by the successive movements in parallel fourth-sixth chords, sixth chords and thirds. In the moments, when we expect the appearance of the dominant, followed by the tonic, the root and the third tone of the dominant triad are heard in the lower texture plan, whereas in the melody appears the first scale degree. This is immediately followed by a descending gradual movement in the harmony down to a subdominant fifth chord (bars 11, 13, 19) or, as it is in bars 7 and 9, the appearance of a dominant fourth-sixth chord in the accompaniment coincides with the sixth degree of the scale in the melody; and instead of the expected next tonic, we hear a fifth scale degree in the melody and a fourth-sixth chord of the sixth scale degree - in the accompanying texture plan. In bars 15 and 17, the repetition of the melodic content of bars 7 and 9 - in the accompaniment, simultaneously with $a^{2}$ appears a sixth chord on the third scale degree, followed by a sixth chord on the second scale degree, i.e. again there is no expressed aggravation. The tonic chord is heard only at the end of the period - in the $21^{\mathrm{st}}$ bar and in the conclusion - the last bar of the piece - bar 26, but in both cases, in the harmony is present one of the leading tones (seventh or second scale degree), forming a dissonance, which brings a certain amount of tension. The dissonances in the tonic triad at the end of the rather complete musical idea, due to the overlay of harmonic seconds, create an acoustic effect of "beating", which could 
be perceived as trembling, cold shivering. The feeling of coldness is intensified by the parallel movements in the lower texture plan in legato (bars 6-9 and 14 - 17), which call out associations of sliding on a smooth icy surface.

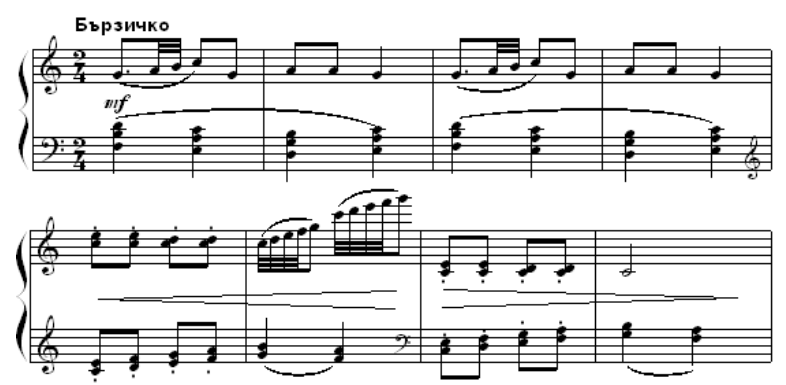

Figure 8. "The Sparrow at the Window”, b. 6-13

The lack of clearly expressed aggravations, which weakens the accompanying role of this texture plan, seems to "alienate", "repulse" the melody - the "song" of the sparrow. This is an extremely laconic, but very powerful way to express the coldness of the winter scene. The plea of the sparrow is depicted through a few insistent repetitions of the motif:

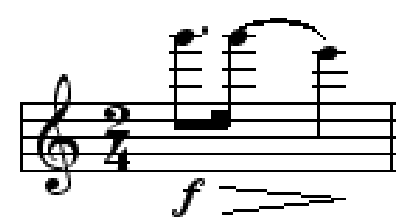

Figure 9. The motif of the sparrow's plea

in a forte dynamic. In such a short piece with such a tiny character, it is expected that its "voice" will be imitated with a quieter dynamic. The elegantly laconic piece clearly enough re-creates both the urgent plea and the intent expectation of an answer in the three one-bar pauses (bar 3,5 and 24), as well as the unresponsive indifference towards the little freezing bird, also - through a "step-by-step" falling from a very high to a medium register in the last onomatopoeic bars, and the fading of the distinct and energetically dotted rhythm of the initial sound-imitating moment in the last bars - the desperation and the despondency of the sparrow.

The ingenuous and entertaining onomatopoeia in the "The Little Hen Laid an Egg" in which the usual cackle of the hen, presented in the introduction and the conclusion (fig. 5), is clearly differentiated from the "triumphant voice" in the culmination, in which the hen "announces" about the laid egg (fig. 6, bars 19 - 22), the memorable build-up to the culmination with a triple gradual overlay of disonating voices in the harmony, distinctly draws the attention of the listener to what follows (fig. 6, bars 13 - 18), as well as the coincidence of the culmination with the point of the Golden Ratio, are all a successful, spectacular and beautiful with its ingenuity way to depict and underline the success of the little heroine.

In the "Cuckoo in the Forest", with very few means two-voiced onomatopoeia in the beginning and single-voiced at the end, and the beautiful but sad melody with gloomy melodic peaks - the composer manages to convey the loneliness of the character.

The wild, primal beauty of the raging tempest in the "The Northern Wind Chases the Swallows" is depicted especially well and impressively in the moment of the build-up to the culmination through an ascending chromatic scale in the two hands, the parallel gamma-like sequences being separated from each other by a tritone.

\section{Conclusions}

1. In the narrated funny stories which with their parable are affined to fables, the beauty of the characters is not only the beauty of their talent and moral qualities, but also of the morally beautiful attitude that the little characters demand from us.

2. The beauty of expression is actually the perfect mastering of the means of expression in music, which are combined in the most concise and influencing way.

3 . The construction of the miniatures is beautiful with its classical regularity, but also with its "functionality" - it is designed to correspond as much as possibble to the ideas, expressed by the composer.

4. Based on these findings, it is clear that the six plays are an intriguing, exciting and useful lesson on aesthetics for the student - pianists, for whom they are intended.

The cycle as a whole is an example of yet another type of beauty - the beauty of invention, of ingenuity and creativeness, of discovering a wonderful in its clarity and brevity way of recreating a character so that it can be perfectly recognized, to breath life into it, to give it emotions and meaning, the beauty of an artist to "dare" to materialize through sound the elusive immateriality of a dream, the beauty to challenge the imagination of the performer and make the listener soar, the beauty of the mind.

\section{References}

[1] Alexeev, Alexander. Interpratation of Musical Works. Based on the Analysis of the Art of the Greatest Pianists of the 20th Century. Moscow, 1984 (Алексеев, Александр. Интерпретация музыкальных произведений. На основе анализа искусства выдающихся пианистов XX века. М, 1984)

[2] Blinova, M. Musical Creativity and the Regularities of Higher Nervous Activity. Leningrad, 1974 (Блинова, M. Музыкальное творчество и закономерности высшей нервной деятельности. Ленинград, 1974)

[3] Fileva, K. G. Methodology of Teaching Piano. Plovdiv, 2011 (Филева, К. Г. Методика на преподаване на пиано. Пловдив, 2011)

[4] Podurovsky, V. M. and N. V. Suslova. Psychological Correction of Music-Pedagogical Activity. Moscow, 2001 (Подуровский, В. М. и Н. В. Суслова. Психологическая коррекция музыкально-педагогической деятельности. Москва, 2001) 
[5] Rabinovich, D. A. Performer and Style. Selected Articles. Issue 1. Moscow, 1979 (Рабинович, Д. А. Исполнитель и стиль. Избранны е статьи. Вып. 1. М, 1979)

[6] Rosen, Charles. Performer's Style and Sound Recording. Notes to a Book. N: Musical Horizons 2/2006 p.27 - 33 (Розън, Чарлз. Изпълнителски стил и звукозапис. Бележки към една книга. В: Музикални хоризонти 2/2006 c. $27-33)$
[7] Shtapov, A. Piano Lesson in Musical Academy and School. Moscow, 2009 (Щапов, А. Фортепианный урок в музыкальной школе и училище. Москва, 2009)

[8] Skrebkova - Filatova, M. S. - Texture in Music. Moscow. 1985 (Скребкова - Филатова, М. С. - Фактура в музыке. М. 1985) 